\title{
Peculiarities and Integration of the pharmaconutriciology Foundation on the Pre-and Post-Graduate Stage of Study
}

\author{
K Smetanina* \\ Department of economics and pharmacy, Faculty of postgraduate education, drug technology and Pharmacoeconomics, Ukraine
}

Received: 制: November 16, 2018; Published: 制: November 27, 2018

*Corresponding author: K Smetanina, Department of economics and pharmacy, Faculty of postgraduate education, drug technology and Pharmacoeconomics, Ukraine

\section{Opinion}

The tendencies to the improvement of educational process in pre-and postgraduate stages of training with emphasis on the need for changes in training programs in education through the implementation process of terminological aspects of preventive medicine and pharmacy direction - farmaconutriciology as one of the important conditions for reforming higher medical (pharmaceutical) educational. The modern system of higher education in Ukraine needs reform. The strategic task here is to train specialists who are knowledgeable about pharmaceutical care, prevention, ethics and deontology. The solution of this problem in pharmaceutical and medical universities is possible through the formation of fundamentally new thinking and changing the outlook on the chosen profession at all stages of the training of a future specialist. Therefore, in order to increase its effectiveness, integration and improvement of existing training programs, creating conditions and incentives for learning as a consequence of improving the efficiency and quality of teaching are needed first of all.

An important aspect of the effective training of a future specialist is the formation of an ideology, starting with the pregraduation phase of training. The real specialist will be only from the student who understands the priorities of his profession. In addition to the formation of ideology, the important integrative moment of each stage of learning is the formation of clinical thinking and the acquisition of practical skills. To master such skills, it is considered necessary to equip training and diagnostic centers, which significantly increases the quality of training and is more humane in relation to the patient. But the arrangement of such centers requires high funding, which is problematic at the present stage of training. Training and diagnostic centers are lacking, and students continue to master practical skills while working with the patient. An important condition for training is the use of bases of specialization centers in which the student will be in practice rather than theoretically acquainted with the specifics of the work of a specialist. A typical example at the postgraduate stage of the training of such centers of specialization should be considered the bases of learning pharmacists-interns. Therefore, it should be considered most expedient in the programs of pre- and postgraduate stage a harmonious combination of work in the clinic with work in the pharmacy.

To acquaint the student with the specifics farmaconutriciology need to start to 3-4 courses stage, when they begin work in a pharmacy, focusing mainly on preventive and consultative direction of the pharmacist. At this time, it would be advisable to start teaching cycles that cover issues of pharmaceutical prophylaxis, ethics, deontology when applying and designating food additives (FA) and dietary supplements (DS) of plant, mineral, animal origin with an emphasis on legal aspects their use. At the practical lessons, the main questions should be the rationality of selecting FA (DS), combining them with drugs, including herbal, homeopathic drugs, attention must be focused on compatibility issues, dose selection, contraindications, restrictions on use. It should be noted that FA (DS) are mainly used for preventive purposes. In some cases, with their help, but under the strict supervision of a dietician or nutriologist, a possible correction of the diet, which requires improvement and / or changes in the tactics of the management of different age patients, especially the elderly. The emphasis should be on the need not just to improve study programs, but 
also to adapt them to the realities of practical pharmacy. It should be emphasized that farmaconutriciology is a widespread trend in the prophylactic use of dietary supplements as drugs with proven efficacy and quality.

Contemporary gaps in legislation, low wages among doctors and pharmacists is the reason for the proliferation of marketing and distribution of FA (DS) in our country. This gives an opportunity not only to raise the financial level of a specialist but also improvement of professionalism due to constant work with scientific informative sources, contact with doctors of narrow specialties, thus gaining experience of working with patients, each of which requires an individual approach not only at selection of doses, choice of optimal schemes of pharmacotherapy taking into account efficiency, efficiency and evidence of the proposed Para pharmaceutical products. Thus, before the higher medical establishments (school), the difficult task of creating conditions for qualitative training of the graduate is currently difficult. The importance of solving this problem is the integration of programs of pre- and post-graduate stage of education, their focus on the formation of prophylactic thinking in the student, adaptation of curricula to the realities of practical pharmacy. Changes in the training programs will allow you to prepare a student with dietary skills, preventive use of vitamins, macro- and microelements, which are mostly the FD (DS) and, accordingly, at the postgraduate stage will increase the professional level by studying the basics of farmaconutriciology, that is, the science of the preventive use of dietary supplements.

\section{ISSN: 2574-1241}

DOI: $10.26717 / B J S T R .2018 .11 .002104$

K Smetanina. Biomed J Sci \& Tech Res

(C) (i) This work is licensed under Creative

Submission Link: https://biomedres.us/submit-manuscript.php

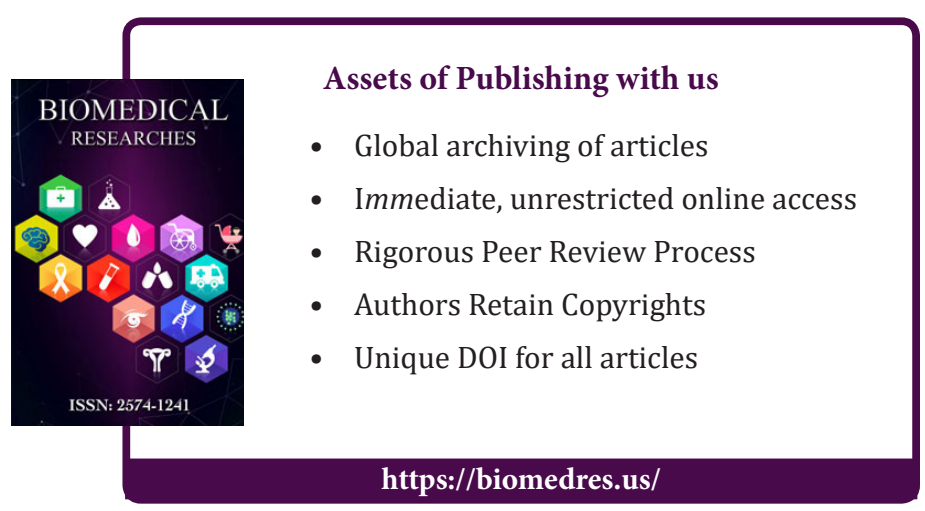

